\title{
The Study of Effervescent Tablet Processing Using Red Roses (Rosa damascena Mill) Pigments Extract
}

\author{
Elfi Anis Saati ${ }^{1}$, Siti Zaenab ${ }^{2}$, Simon Bambang Widjanarko ${ }^{3}$ and Yunianta $^{3}$ \\ 1. Department of Science \& Food Technology, Faculty of Agricultural \& Animal Husbandry, Muhammadiyah University of Malang, \\ Malang 65145, Indonesia \\ 2. Department of Biology, Faculty of Teacher Training and Science, Muhammadiyah University of Malang, Malang 65145, \\ Indonesia \\ 3. Department Food Technology, Faculty of Agricultural Technology, Brawijaya University, Malang 65145, Indonesia
}

Received: July 7, 2011 / Published: February 20, 2012.

\begin{abstract}
Rose is one of the farming products that used as an accessory plantation, which is also known to contain vitamin C and anthocyanins which can be used as an antioxidant. The purpose of this study is to identify the colour effect of flower through the quality effervescent tablet, to know the interaction between the flower colour and the sugar type through the quality effervescent rose tablet. This study was done with two steps. Step I was divided into 2 levels of examinations using simple random: Rose colouring, M1 (dark red) and M2 (pink), while step II consisted of three levels of examinations, those were G1 (sucrose), G2 (dextrose), and G3 (sorbitol). The result showed that the dark red colour has a better extract pigment quality, the level of the light color (L) was 77.3 and the redness level ( $\mathrm{b}+$ ) was 25.033 . The best rose effervescent tablet was produced by the combination of M1G3 (dark red: corn sugar/sorbitol), that has $8.179 \%$ of water content; the solute velocity was $0.029 \mathrm{~g} / \mathrm{sec}$; the lightness level (L) was 84.133, the redness level (a+) was 18.3 . The product of the rose effervescent drinks has a value of $6.46 \mathrm{pH}$; viscosities $342.867 \mathrm{cps}$ and total of sugar 52.150\%.
\end{abstract}

Key words: Red rose, anthocyanin, pigment, effervescent.

\section{Introduction}

Rose (Rosa damascena Mill) is one of the plants functioning as a decorative plant. The corolla/petal rose contains anthocyanin pigment that is classified into flavonoid [1, 2] and functions as antioxidant substances that could catched free radicals [3-5], and has possed known pharmacological properties [6-9]. The rose's corolla/petals can be used as a medicine, that can be consumed in drink as roses essence in formula product such as effervescent tablet. The study of processing rose's petal to form an effervescent tablets is to find the merit of rose so that it can be utilized especially as a natural antioxidant due to the vitamin $\mathrm{C}$ and anthocyanin contained [10-12], as an effort to

Corresponding author: Elfi Anis Saati, Ph.D. candidate, research fields: natural colorant and bioactive/antioxidant from pigment. E-mail: elfiumm@yahoo.co.id. diversify rose's petals products. Effervescent tablets enables the rose extract containing beneficial component to be consumed instantly. Furthermore, it can increase the economic value of rose flower. It is also to fulfill consumers' need whereby the consumers nowadays tend to consume natural substance ("back to nature”). They are now aware that they should avoid synthetic ingredients and consume safe products instead.

The main ingredients in effervescent tablets product are the red and pink local variety of rose. The reason for choosing the local rose because of good supply, affordable price and the short period of display. Futhermore, the use of Tropicana slim sugar aims to give a special merit to the diabetic person because it contains sorbitol sugar. Using sorbitol is non-carcinogenic (does not cause cancer) [13], on the 
contrary it is useful for the diabetes mellitus sufferer because sorbitol has only a low level of calorie.

The objectives of the study are as follows:

(1) To identify the influence of the colour of rose on extract powders of rose pigment quality.

(2) To identify the influence of the rose colour interaction with sugar type in rose effervescent tablet quality.

\section{Materials and Method}

\subsection{Materials}

The main ingredients needed were local variety of the rose obtained from a farmers in Gunungsari village, of city Batu-East Java Indonesia. The chosen roses were the red and pink roses. The others ingredients were aquadest, maltodextrim, citrate acid, sodium bicarbonate, and three kinds of sugar: sucrose, dextrose and Tropicana slim.

\subsubsection{Tools}

The tools used were a strainer, a calibrated beaker glass, a pair of scales, a blender, a brass, a cabinet dryer, a 60-mesh sieve, a hydraulic press, a tablet mould, stainless metal ring and a chromed stainless steel-pounder with $10 \mathrm{~cm}$ in length and the outer diameter was $2.6 \mathrm{~cm}$; whereas the analysis tools were a beaker glass, calibrated beaker, an erlenmeyer, a beaker glass, a goiter pipette, a pH meter (pH315i/SET brand: wtw), colour reader (CR-10 Konica Minolta), a hardness tester (Kiya Seisakusho, Ltd Tokyo), and an oven.

\subsection{Research Method}

The research was conducted in two step with three repetitions. Step I was to examine the pigment quality of red rose from two factors of rose with two colour levels of red rose, M1 (dark red) and M2 (pink) that was done using Simple Complete Random Design.

Step II used the Factorial Group Random Design, the first factor contained 2 levels of experiment $\left(\mathrm{M}_{1}\right.$ : Black Red Rose; $\mathrm{M}_{2}$ : Pink Rose), and the second factor contained 3 levels of experiment (types of sugar: $G_{1}$ : Sucrose; $G_{2}$ : Dextrose; $G_{3}$ : sorbitol/corn sugar).

\subsubsection{Research Performance}

Processing the Powder of Rose's Pigment Extract

(1) Preparing the corolla/petals of dark red and pink roses;

(2) The selected corollas were measured at the rate of $45 \mathrm{~g}$, add the solvent, aquadest and citrate and blend them afterwards;

(3) Kepping the blended ingresients in the refrigerator for 30 minutes and then separating the liquid from dregs;

(4) Adding 30\%-40\% of filler maltodextrin;

(5) Drying the ingredients in the cabinet dryer at $50{ }^{\circ} \mathrm{C}-60^{\circ} \mathrm{C}$;

(6) Shifting the dried ingredients at 60-mesh.

Processing Rose Effervescent Tablet

The powder of rose extract from the previous processing was made as effervescent with the following process:

Mixing $100 \mathrm{~g}$ of rose extract powder with $20 \%$ citrite and $30 \%$ of sodium bicarbonate using a blender;

After getting the nucleus/core granule, mixing the nucleus granule (30\%) with sugar (sucrose, dextrose and sorbitol/corn sugar) in $70 \%$ rate.

The mixed ingredients were sifted at 60-mesh, condensing/pressing the shifted material into tablet and then packing them in aluminium foil.

\subsubsection{Monitoring Parameter}

The analyses were done both to the powder of rose extract and rose effervescent tablet covered the chemical, physical and organoleptical analysis. The analysis done consisted of water content, $\mathrm{pH}$, colour intensity, whereas for the effervescent tablet, the analysis covered the water content, $\mathrm{pH}$, total of solutal density, soluble rapidity, viscocity, hardnesss level, and colour intensity.

\section{Result and Discussion}

\subsection{Analysing Extract Powder of Rose’s Pigment}

3.1.1 The Water Content and pH Analysis of Rose's Pigment Powder

There is difference in average value of water content 
in the extract powder of rose pigmentof red and pink rose's pigment as result of flower colour treatment. It shown that the red rose in average has a high water content with $6.652 \%$ level, while the average of water content in pink rose in lower, that is $5.953 \%$. It is caused by the thickness of the structure of red rose's corolla, as it is thicker than the pink rose's so the wate evaporation is slower. This fact is supported by Tranggono [14] who suggested that the maximum water of certain network can largely be different because of the difference in sctucture. It is also largely influenced by plant condotion.

The $\mathrm{pH}$ value of rose's pigmentcaused by treatment is also different. The experiment shows that the dark red roses has a lower level of $\mathrm{pH}$ that is 2.877; while the the pink rose has 2.920 of $\mathrm{pH}$ value. These $\mathrm{pH}$ levels are lower than the result of research conducted by Mustofa [15] showed that the powder of rose's pigment extract had the $\mathrm{pH}$ level of about 3.320. It was caused by adding the citrate, a strong organic acid [16], while extraction that influenced the condition of water solvent made it more acid due to the stable anthocyanin is in acid condition (low $\mathrm{pH}$ ).

3.1.2 The Color Intensity Analysis of Rose's Pigment Powder

The treatment of red roses results in a lower brightness (L) level, that is 77.3; while brightness (L) level of pink rose is higher, that is 92.3. The darker the colour of flower, the lower the brightness (L) level it has. On the country, the brighter the colour of the flower, the higher the brightness level it has.

The increase of brightness ( $\mathrm{L}$ ) level is inversely proportional to the redness level $\left(\mathrm{a}^{+}\right)$. The treatment of the dark red rose contributes to the higher redness level $(\mathrm{a}+)$ that is 25.033, while the treatment of pink rose has a lower redness level $\left(a^{+}\right)$that is 6.733 . The increase of the redness level $\left(a^{+}\right)$shows the high contribution of red colour. It is because in the acid $\mathrm{pH}$, the dominant component is cation flavium so it appears as the red colour, meaning it contains anthocyanin [17].

The redness level $\left(\mathrm{a}^{+}\right)$of rose's pigment is also influenced by genetic factors and character of each type of flower [18]. The important characteristic of rose planted by the farmers in Batu have a pre-eminent colour such as dark red to black in the edge of petal, which had 27-40 pieces, beautiful petal, had life phase of about 7-8 days, durable, resistancy delivery for long distance, and the production each plant was about 5-6 pieces a month. It has dense, rather stiff, thick and gloddy petals. It can also planted without shelter or shade [19, 20].

In the color intensity anlaysis, the pink rose has the higher blueness level (b-) of 3.067, while the dark red rose has the lower blueness level (b-) of 2.833. The appearance of the blue colour causes the pigment to look red that is quite bluish/purplish (the mixing of red and a little blue).

\subsection{The Analysis of Effervescent Tablet}

3.2.1 The Water Content Analysis of Effervescent Tablet

In the treatment of G2 (dextrosse), it has the water content that is definitely different from the treatment of G3 (sorbitol/Tropicana slim) and the treatment of G1 (sucrose). The highest water content, that is $16.744 \%$, was obtained in the treatment of G2, while the lowest level treatment is obtained from the treatment of G1 (sucrose) with $4.012 \%$. When it is compared to the water content of effervescent Calcium-D-Redoxon tablet as a control that has $0.993 \%$ level, the water content in effervescent rose tablet remains overly high. It is caused by the dextrose sugar that has more hygroscopic (has the open bond) characterictis than sucrose and Tropicana slim sugar, so easier to bind $\mathrm{H}_{2} \mathrm{O}$ in the vicinity [2].

\subsubsection{Analysis of $\mathrm{pH}$ Level}

The average level of $\mathrm{pH}$ in the solution of rose effervescent tablet as a result of flour colour treatment is relatively equal. The tablet, the result from Tropicana slim sugar (G3), has a higher $\mathrm{pH}$ level, that is 6.590, than the $\mathrm{pH}$ resulting from the sucrose (G1) and G2 (dextrose) which are about 6.420 to 6.470. As a 
quality comparison of effervescent rose tablet, the researcher used the parameter of $\mathrm{pH}$ level from effervescent Calcium-D-Redoxon, that is 6.900, that has the close level.

3.2.3 The Analysis of Color Intensity and the Level of Solidity (Texture) of Rose Effervescent Tablet

The highest lightness level (L) is 95.000 that is a result from the treatment of M1G2 (dark red: Dextrose) with the lightness level of 81.633 (Table 1). It is caused by the influence of flower colour, where the rose with the red flower has a quite thick and blackish corolla. The low lightness level indicates the existence of more anthocyanin content. It can be identified from the increase of redness level $\left(a^{+}\right)$.

The level of redness $\left(\mathrm{a}^{+}\right)$of rose effervescent tablet using the drak red flower treatment is about 14.467 to 18.300 that is higher than the treatment of pink rose that is only about 4.100 to 5.167 . The Red colour indicates the existence of anthocyanin pigment, because this pigment that in the acid $\mathrm{pH}$, the dominant component is cation flavium so the colour from the solution contains the pure anthocyanin that appears to be the red colour [21].

The results of comparison examination DMRT 5\% indicates that the large treatment difference is the treatment M1G1 (dark red rose: sucrose) that has the yellowness level $(\mathrm{b}+) 2.067$ compared to the treatment of M2G3 treatment (pink-sorbitol/corn sugar Tropicana slim) that has the (-) 3.967 yellowness level. The yellowness level will increase along blueness level is rising up. It is presumed to be caused by type of anthocyanin pigment contained in rose pigment that tends to have the purplish red colour. It is compatible with Nollet [21] argumentation that it is the colour characteristic of anthocyanin pigment. It is also supported by the statements of Stanciu et al. [22] and Lewis et al. [16] that there was presenced of other compounds such as flavonoids, proteins, minerals and various sugars such as this treatment could affected the stability of anthocyanin, which was characterized with colour intensity.

The treatment of M1G2 (red: dextrose) has the lowest hardness level that is $9.167 \mathrm{~kg} / \mathrm{cm}^{2}$. While the treatment of M2G1 (pink: sucrose) is a treatment with the highest hardness level that is $21.000 \mathrm{~kg} / \mathrm{cm}^{2}$. It is lower than the effervescent of Calcium-D-Redoxon tablet that is $37 \mathrm{~kg} / \mathrm{cm}^{2}$. It is caused by the rose effervescent tablet that is produced has been absorbing the water from its surround because of its hygroscopic material, and the hardness level is lower than the controller. The high rate of density will influence the tablet soluble rapidity and viscosity of solution produced. It is in line with research results, which proposes that the insufficient harmony in a tablet can be caused by the low humidity, too dry granule so the ingredients form the capping and lamination [23, 24].

The characteristics of sugar type also influence the lightness rate of tablet. Sucrose sugar has whiter colour than dextrose sugar. Therefore, treatment using sucrose has the higher lightness level. However, Tropicana slim sugar which is a combination of sorbitol sugar and aspartame obtained the highest lightness. It is because the aspartame is a crystal white powder. While sorbitol is a compound which is white granuled or crystaled [25].

Table 1 The Means of color intensity and level of solidity (Texture) of rose effervescent tablets.

\begin{tabular}{llccc}
\hline \multicolumn{4}{l}{ Treatment } & \multicolumn{3}{c}{ Colour intensity } & The Solidity level of tablet $\left(\mathrm{kg} / \mathrm{cm}^{2}\right)$ \\
\hline & Value L & Value a + & Value b \\
\hline M1G1 (Red: Sucrose) & $84.067 \mathrm{~b}$ & $14.467 \mathrm{~b}$ & $-2.067 \mathrm{~d}$ & $10.333 \mathrm{~b}$ \\
MIG2 (Red: Dextrose) & $81.633 \mathrm{a}$ & $16.133 \mathrm{c}$ & $-2.533 \mathrm{c}$ & $9.167 \mathrm{a}$ \\
M1G3 (Red: Tropicana Slim) & $84.133 \mathrm{~b}$ & $18.300 \mathrm{~d}$ & $-2.733 \mathrm{~b}$ & $11.367 \mathrm{~b}$ \\
M2G1 (Pink: Sucrose) & $91.467 \mathrm{c}$ & $4.900 \mathrm{a}$ & $+2.867 \mathrm{~b}$ & $21.000 \mathrm{~d}$ \\
M2G2 (Pink: Dextrose) & $92.367 \mathrm{~d}$ & $5.167 \mathrm{a}$ & $+2.933 \mathrm{~b}$ & $11.167 \mathrm{~b}$ \\
M2G3 (Pink: Tropicana Slim) & $95.000 \mathrm{e}$ & $4.100 \mathrm{a}$ & $+3.967 \mathrm{a}$ & $14.500 \mathrm{c}$ \\
\hline \multicolumn{7}{l}{ The average rate with the same letters in the same columm indicates that there is significant difference with the Dunan (DMRT) 5\% } \\
examination.
\end{tabular}


3.2.4 The Analysis of Viscovity in Rose Effervescent Solution

The lowest viscovity value is in the treatment of sucrose sugar (G1) that is $31.227 \mathrm{cps}$, where this value is remain too high comparing to viscovity value of effervescent Calcium-D-Redoxon as a control that is only 9.400 cps. The viscovity level is influenced by the density of tablet. If the viscovity level is higher, the density will be low so the tablet structure will be brittle. Consequently, the time needed to be soluble is quicker. The treatment with dextrose sugar has the highest total density compared to the other type of sugar. It caused 1 gram dextrose sugar can dissolve in $1 \mathrm{~mL}$ of water, and sucrose sugar can dissolve in 0.5 $\mathrm{mL}$ of water in room temperature [14]. It is different with Tropicana slim sugars which consist of sorbitol sugar and aspartame within. Sorbitol is the granulled compound or crystal which is white, sweet, and hygroscopic with melting point about $89{ }^{\circ} \mathrm{C}-101{ }^{\circ} \mathrm{C}$ [13]. While, aspartame is a compound that is odorless, in white crystal powder form, quite water soluble, and has sweet taste.

3.2.5 The Analysis of Total Density and the Soluble Rapidity of Rose Effervescent Tablet

Based on DMRT 5\% examination, it is known that the average of total density of effervescent tablet in the treatment of flower colour with sugar type is about 0.649 to $2.105 \mathrm{~g} / \mathrm{mL}$. The treatment of M1G2 (dark red: dextrose) has the highest total density that is 2.105 $\mathrm{g} / \mathrm{mL}$ (Table 2). It indicates that the red dark rose has more total density with the more existance of anthocyanin as an indicator. The rate of solutal density is supported by the total content of sugar. As information on the results of previous studies that the total content of sugar in dark red rose is $10.1 \%$, while the sugar content of pink rose is $8.0 \%-10 \%$ [5].

Based on the DMRT 5\% comparison examination, it is known that the rose effervescent tablet that is resulted from the interaction of flower colour treatment with Corn sugar/Tropicana slim sugar type (G3) is quickest/fastest to dissolve in solvent (water) than the sucrose and dextrose sugar, which amounted 0.029 for M1G3 and $0.32 \mathrm{~g} / \mathrm{sec}$ for M2G3. While the lowest rapidity soluble is the treatment which uses the sucrose (G1) that is about $0.066-0.078 \mathrm{~g} / \mathrm{sec}$, while the treatment of dextrose sugar (G2) has the soluble rapidity about $0.070-0.091 \mathrm{~g} / \mathrm{sec}$. As the quality comparison of rose effervescent tablet, the researcher uses the effervescent Calcium-D-Redoxon tablet which has the slower soluble rapidity that is $0.030 \mathrm{~g} / \mathrm{sec}$. It is caused by the low density level of the tablet so it is brittle easily and the result that the needed time to dissolve is quicker.

Furthermore, the thicker corolla's petal of red rose make the total component of soluble anthocyanin pigment in the extracting process is more than the total in pink rose. The treatment of Tropicana slim sugar shows the real different with the total solutal density compare to sucrose and dextrose. It is because Tropicana slim is consisted of sorbitol and aspartame. Sorbitol is the granulled compound or crystal which is white, sweet, and higroscpic with melting point about $89{ }^{\circ} \mathrm{C}-101{ }^{\circ} \mathrm{C}$ [13]. While, aspartame is a compound that is odorless, in white crystal powder form, quite water soluble, and has sweet taste. While aspartame is a compound that is composite from aspartat, fenil-alanin

Tabel 2 The average level of total density and soluble rapidity of rose effervescent tablet.

\begin{tabular}{lll}
\hline Treatment & The Total Density Level (g/mL) & Soluble Speed/Rapidity (g/sec) \\
\hline M1G1 (Red : Sucrose) & $2.027 \mathrm{~b}$ & $0.078 \mathrm{c}$ \\
MIG2 (Red : Dextrose) & $2.105 \mathrm{~b}$ & $0.091 \mathrm{c}$ \\
M1G3 (Red : Corn sugar) & $0.649 \mathrm{a}$ & $0.029 \mathrm{a}$ \\
M2G1 (Pink : Sucrose) & $0.767 \mathrm{a}$ & $0.066 \mathrm{c}$ \\
M2G2 (Pink : Dextrose) & $0.735 \mathrm{a}$ & $0.070 \mathrm{c}$ \\
M2G3 (Pink : Corn sugar/ Tropicana Slim) & $0.672 \mathrm{a}$ & $0.032 \mathrm{~b}$ \\
\hline
\end{tabular}

The average rate with the same letters in the same column shows that the experiment result is not really different with Duncan (DMRT) 5\% examination. 
and methanol so it has more complex interaction [26] with anthocyanin pigment which is a polifenol, so the pigment tablet that is produced is more solid and the density of component of compound is more solid) than the sucrose and dextrose sugar type. While, its soluble rapidity is caused by the characteristics of each type of sugar where Tropicana slim has more hydroxyl cluster and ketone cluster that is easy-water soluble.

\section{Conclusions}

The flower colour influence the quality of rose pigment extract powder, especially in the redness level $(\mathrm{a}+)$ and lightness level of rose's pigment effervescent tablet. The interactions between flower's colour and the sugar type influence the quality of rose effervescent tablet that is produced, especially on the soluble rapidity, total density, and colour intensity of rose pigment effervescent tablet. The best effervescent tablet is produced by the combination between the treatment of dark red rose with sorbitol/corn sugar type (M1G3) which has $8.179 \%$ water content, $11.5 \mathrm{~kg} / \mathrm{cm}^{2}$ of hardness level, $0.029 \mathrm{~g} / \mathrm{sec}$ of soluble rapidity, 84.133 of brightness level, 18.3 redness level $(\mathrm{a}+)$, redness level $(\mathrm{a}+)$ 18, 3 2,733 of yellowness level (b), 6.46 ph value, 32,867 cps of viscosity and $0,814 \mathrm{~g} / \mathrm{g}$ of total density.

\section{Acknowledgments}

The researcher thanks Research and Dedication to Society Directorate of DIKTI who had been registering the patent right of title: Effervescent tablet of Pigments Red Roses (Rosa $s p$ ) and this process manufacturing. Number Inventor P00200900698.

\section{References}

[1] P. Markakis,. Anthocyanins as Food Colors, Avademic Press, New York, 1982, p. 263.

[2] O.R. Fennema, Food Chemistry, 3rd ed., Marcel Dekker, inc., New York, 1996.

[3] L.P. Leong, G. Shui, Aninvestigation of antioxidant capacity of fruits in Singapore markets, Food Chemistry 76 (2002) 69-75.

[4] F.L. Hu, R.L. Lu, B. Huang, L. Ming, Free radical scavenging activity of extracts prepared from fresh leaves of selected Chinese medicinal plants, Fitoterapia 75 (2004) 14-23.

[5] Sukardi, E.A. Saati, The PHB Report, Utilization As a Sort of Roses Pigments Dyes and Antioxidant Natural Substances in Food Products, DP2M DIKTI RI Year 2006.

[6] C. Wang, J. Wang, W. Lin, C. Chu, F. Chou, T. Tseng, Protective effect of Hibiscus anthocyanins against tert-butyl hydroperoxide-induced hepatic toxicity in rats, Food and Chemical Toxicology 38 (2000) 411-416.

[7] D. Cooke, W.P. Steward, A.J. Gescher, T. Marczylo, Anthocyans fromfruits and vegetables-Does bright colour signal cancer chemopreventive activity, European Journal of Cancer 41 (13) (2005) 1931-1940.

[8] C. Pergola, A. Rossi, P. Dugo, S. Cuzzocrea, L. Sautebin, Inhibition of nitric oxide biosynthesis by anthocyanin fraction of blackberry extract, Nitric. Oxide. 15 (2006) 30-39.

[9] G.A. Garz'on, K.M. Riedi, S.J. Schwartz, Determination of anthocyanins, total phenolic content, and antioxidant activity in Andes Berry (Rubus glaucus Benth), J. Food Sci. 74 (2009) 227-232

[10] S. Blake, Medicinal Plant names, Sample expert, Artikel, 2004, http: www. NaturalHealthWizardCom./MedicinalPlantNames, Sample.html.pdf (accessed on 12 August 2010).

[11] Tanaka Yoshikazu, Filippa Brugliera, Steve Chandler, Recent progress of flower colour modification by biotechnology, Int. J. Mol. Sci. 10 (2009) 5350-5369.

[12] Z.D. Yang, W. Zhai, Identification and antioxidant activity of anthocyanins extracted from the seed and cob of purple corn (Zea mays L.), Innovative Food Science and Emerging Technologies 11 (2010) 169-176

[13] Adi. Darmawan, Sorbitol, Sweeteners for Diabetics, 2005, http://www.suaramerdeka.com (accessed on February 11 2009).

[14] Tranggono, Nutrition and Food Chemistry, PAU Food and Nutrition, Universitas Gadjah Mada, Yogyakarta, 1990.

[15] Z. Mustofa, The study of effervescent tablets from extracts red roses (Rosa sp.): Study of varieties flower, type of solvent and sugar type, Department of Agricultural Product Technology, Faculty of Agriculture, Muhammadiyah University of Malang, 2008.

[16] D.H. Lewis, S.J. Bloor, K.A. Mitchell, Flower Colour in Cymbidium, What Makes up The Colour You See?, 1997, http://www.crop.cri/nz/meidakit/Release/971308835.htm.

[17] J. Li, Total anthocyanin content in blue corn cookies as affected by ingredients and oven types, Disertation, Department of Grain Science and Industry College of Agriculture, Kansas University, Manhattan, Kansas, 2009, p. 111.

[18] S. Kuwayama, S. Mori, M. Nakata, T. Godo, M. Nakano, 
94 The Study of Effervescent Tablet Processing Using Red Roses (Rosa damascena Mill) Pigments Extract

Anthocyanidins and anthocyanins in lychnis flowers, Bull. Facul. Agric. Niigata Univ. 58 (2005) 35-38.

[19] T. Purbiati, Tuniarti, N.S. Darliah, Samayanti dan D. Sulistyowati, Introduction of Candidates for Superior Variety Cut 2006, http://www.bptp-jatim-deptan.go.id/kontak.html (accessed on August 13 2006).

[20] R. Rukmana, Rose, Kanisius Publisher, Yogyakarta, 1995, p. 58.

[21] L.M.L. Nollet, Hand Book of Food Analysis, 2nd ed., Marcel Dekker, Inc., New York, 1996, p. 1088.

[22] G. Stanciu, L. Simona, S. Constanta, S. Zagan,
Spectrophotometric study on stability of anthocyanins extract from black grapes skins, Ovidius University Annals of Chemistry 21 (2010) 101-104.

[23] H. Ansel, Introduction to Process of Pharmaceutical Preparations, 4th ed., UI Press, Jakarta, 1989.

[24] R. Voight, Textbook Pharmaceutical Technology, 2nd ed., Interpreter: Soendani, Gadjah Mada University Press, Yogyakarta, 1995.

[25] Calorie Control Council, Health professional's opinions on aspartame, 2002.

[26] J.M. De Man, Principles of Food Chemistry, 3rd ed., Aspen Publishers, Inc. Gaithersburg, Maryland, 1999. 